\title{
Deglacial Ocean Circulation and Carbon Cycling
}

\author{
Andreas Schmittner', S.L. Jaccard ${ }^{2}$, A.C. Mix ${ }^{1}$ and E.L. Sikes ${ }^{3}$ \\ Inaugural OC3 Workshop, Bern, Switzerland, 1-3 October 2014
}

The stable isotopes of carbon $\left(\delta^{13} \mathrm{C}\right)$ provide a uniquely valuable tracer of the carbon cycle, and are an essential component for understanding changes in the Earth's various carbon reservoirs and their relation to climate change. Its spatial distribution in the ocean is affected by circulation and fractionation during gas exchange, and carbon cycling. Foraminifera, which are microscopically small animals living near the surface (planktic) or in/on the sea floor (benthic species), incorporate the dissolved inorganic carbon (DIC) isotopic signature of the water $\delta^{13} C_{D I C}$ into their calcium carbonate shells, which are eventually preserved in the sediments providing a glimpse into past $\delta^{13} C_{\text {DIC }}$ levels. Ever since the first comparison of foraminifera $\delta^{13} \mathrm{C}$ data $\left(\delta^{13} \mathrm{C}_{\text {foram }}\right.$ ) from core-top sediments with water column $\delta^{13} \mathrm{C}_{\text {DIC }}$ measurements (Duplessy et al. 1984), paleoceanographers have used $\delta^{13} \mathrm{C}_{\text {foram }}$ as a proxy to reconstruct past changes in ocean circulation and other environmental variables. The record is more complex than originally assumed, however, and to advance understanding requires careful consideration of these complicating factors.

The goal of the new PAGES "Ocean Circulation and Carbon Cycling" working group OC3 (www.pages-igbp.org/workinggroups/oc3) is to synthesize sedimentary $\delta^{13} \mathrm{C}$ data in order to reconstruct changes in ocean circulation and carbon cycling over the last deglaciation. This time period is of particular interest since it was characterized by overall global warming and large changes in the climate system and the carbon cycle. In addition there exist well-constrained paleo-records at high temporal resolution, with a reasonable spatial distribution.

The kick-off OC3 meeting was held backto-back with the related International Quaternary Association's International Focus Group IPODS (Investigating Past Ocean Dynamics) in order to exploit existing connections and foster collaboration between both working groups. IPODS has similar goals of understanding deglacial circulation changes but focuses on different proxies, such as radiocarbon, and other dynamic proxies of ocean circulation $(\varepsilon N d, \mathrm{~Pa} / \mathrm{Th})$. Here we only report on the OC3 part of the workshop. The IPODS report is available elsewhere (Skinner and Schmittner 2014).

OC3 presentations included new efforts to simulate $\delta^{13} \mathrm{C}$ in comprehensive Earth System Models, simulations of deglacial changes using intermediate complexity models, and inverse modeling of the modern- and Last Glacial Maximum (LGM, 23-19 ka BP) ocean. Compilations of available data as well as new downcore records of $\delta^{13} \mathrm{C}$ from the Atlantic and the Pacific oceans showed coherent

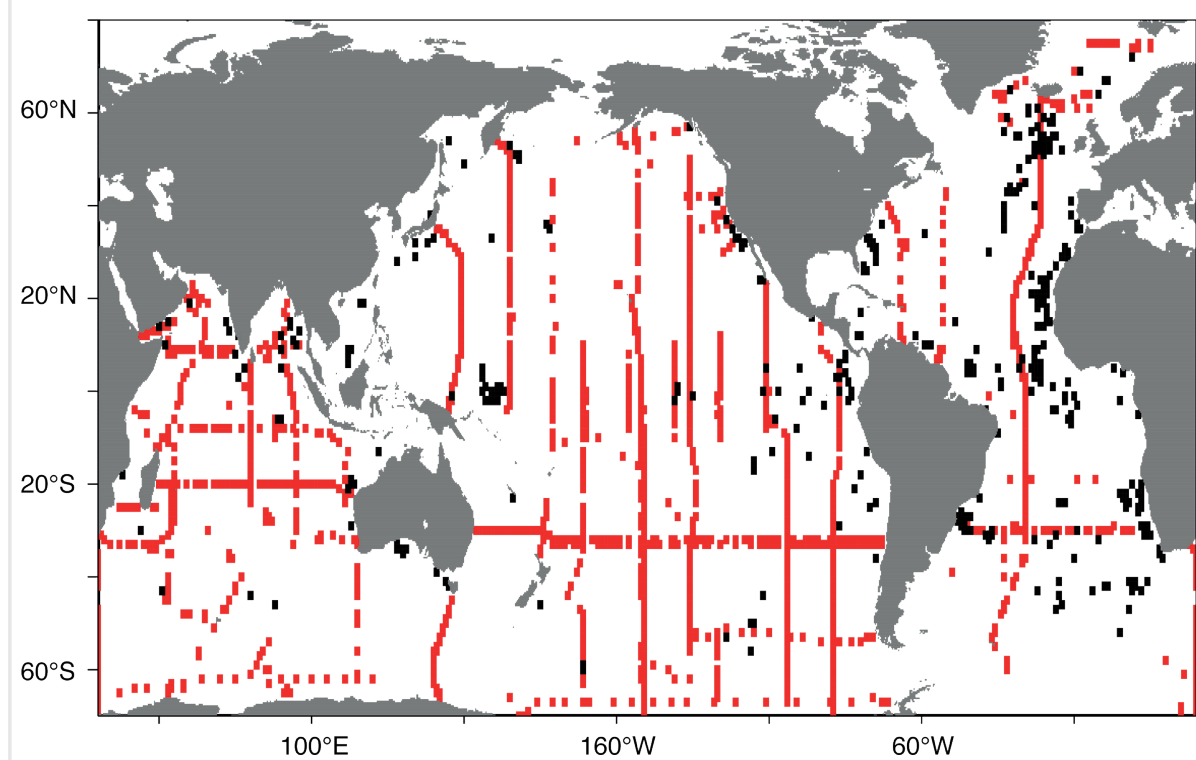

Figure 1: Map of available $\delta^{13} \mathrm{C}_{\text {foram }}$ data (on a $1^{\circ} \mathrm{grid}$ ) from core-top sediment foraminifera (black; Pederson et al. 2014 plus unpublished data from $A$. Mix) and water column $\delta^{13} C_{D I C}$ (red) measurements. These two datasets will be used for calibrations. changes consistent with the interpretation that the deep ocean circulation changed particularly strongly in the Atlantic and at mid depths during the Heinrich Stadial 1 (HS1, 19-15 ka BP), whereas deeper layers in the South Atlantic and South Pacific changed later during the Bølling-Allerød (15-13 ka BP) coeval with the Antarctic Cold Reversal and the Younger-Dryas (13-12 ka BP).

One session explored uncertainties of $\delta^{13} C_{D I C}$ reconstructions. Carbonate ion concentrations have been shown to lead to species-specific offsets between planktonic foraminifera $\delta^{13} \mathrm{C}_{\text {foram }}$ and the water column $\delta^{13} C_{D I C}$ (Spero et al. 1997).

One of the immediate goals of OC3 is to update the original global calibration against seawater $\delta^{13} C_{D I C}$ of benthic $\delta^{13} C_{\text {foram }}$ of Duplessy et al. (1984) by using a much larger database of both water column and core-top sediment data. Figure 1 shows the current distribution of both datasets. Preliminary analysis of these data indicates that the carbonate ion effect is also present in the benthic $\delta^{13} \mathrm{C}_{\text {foram }}$ data.

Discussions during breakout groups and within the plenary focused on details of data synthesis such as metadata needed, formats, and conventions for archiving individual data sets, and retrieval methods. Finally, a strategy and plan for the next steps was developed that cuts out the work until the next meeting, which will presumably be held in 2015.

\section{AFFILIATIONS}

${ }^{1}$ College of Earth, Ocean, and Atmospheric Sciences, Oregon State University, Corvallis, USA ${ }^{2}$ Institute of Geological Sciences, University of Bern, Switzerland

${ }^{3}$ Institute of Marine and Coastal Sciences, Rutgers University, New Brunswick, USA

\section{CONTACT}

Andreas Schmittner: aschmitt@coas.oregonstate.edu REFERENCES

Duplessy J-C et al. (1984) Quat Res 21: 225-243 Peterson CD et al. (2014) Paleoceanography 29: 549-563 Schmittner et al. (2013) Biogeosciences 10: 5793-5816 Spero HJ et al. (1997) Nature 390: 497-500 